\title{
EDITORIAL
}

\section{The Economics of Nature: Using economics methods to value, protect and restore nature}

\section{INTRODUCTION}

Over the last few millennia, human actions have drastically altered the natural landscape. As a result, over $50 \%$ of the forests that existed at the beginning of agriculture have been converted to human-dominated landscapes while increasing the species extinction rate by as much as 1,000 times and converting intact natural land at a rates of over $1 \%$ annually. These figures are published in the Millennium Ecosystem Assessment (MEA), a global study conducted in 2005 involving over 1,400 scientists and practitioners, to understand the status of the natural environment (MEA 2005). It concludes that ecosystems, the dynamic and complex of plant, animal and microbial communities and their physical environments are disappearing.

The loss of natural ecosystems has a direct impact on human welfare as human existence and life on earth more generally are depend on the outputs and benefits from healthy and functioning ecosystems. The MEA defines these benefits and outputs from ecosystems as 'Ecosystem Services' such as food, freshwater, timber, climate regulation, protection from natural hazards, erosion control, pharmaceutical ingredients and recreation. As highlighted in the MEA (Figure A in the synthesis report), human well-being is directly and indirectly linked to the services derived from ecosystems.

If nature and nature's benefits (more technically ecosystems and ecosystem services) are fundamentally essential to human survival, the natural question becomes why are ecosystems being converted and destroyed at a rapid rate? A second global effort that brought together experts, practitioners and policy makers tried to find answers to this question under the Economics of Ecosystem Services and Biodiversity (TEEB) project (TEEB, 2010). This work identifies the invisibility of nature in the decision and policy making arena as one of the key causes for habitat and ecosystem loss. At present, our market based economic system does not accurately reflect or incorporate the value of ecosystem services.

For example, consider building a road that connects two cities on opposite edges of a forest. One option would be to build the road through the forest and the second option would be to build the road around the forest, presumably at a longer distance and most likely over private farm land. Our current economic models can measure the increase in output, in terms of creating jobs and the value added to the economy with the construction of the road. The information on the direct construction cost of the road and cost on compensation payment for private landowners will also be available. In this setting, most policy makers would opt to build the road through the forest as limited quantified data is available on the benefits of the forest and on the losses of these benefits once the forest is cleared for the road.

The TEEB framework attempts to address this issue by compiling and synthesizing methods that enable us to reduce invisibility of nature in policy and economic decision-making processes. These methods focus on (1) reducing and eliminating the lack of information flows (reducing externalities) and (2) using efficient methods for resource allocation to guide conservation and protection of nature. This editorial briefly introduces these methods that economists use to value, protect and restore nature.

\section{PROTECTING AND RESTORING NATURE}

Ideally, conservation areas should be earmarked to protect the biodiversity and ecosystems. Unfortunately, this would require a large amount of land and financial resources, both of which are scarce. Thus, the problem of allocating land and resources for conservation becomes an economic issue as much as it is ecological.

Systematic conservation methods (or optimal site selection or reserve design methods) identify optimal conservation areas based on ecological and economical constraints and resources. However, early models focused purely on the conservation outcomes. Later on, the models have expanded to incorporate economic considerations such as land prices, threat of development, spatial considerations (connectedness and clustering), and dynamic aspects (changes in land prices and land availability).Williams et al. (2005) and Boyd et al. (2015) provide extensive reviews of this early work. The most recent work has explicitly focused on modeling the uncertainty and changing habitats due to climate change (Ando and Mallory, 2002; Dissanayake and Hennessey, 2017).

The growing academic literature on systematic conservation methods has led to the creation of multiple software tools that can be used by both academics and practitioners to model and guide conservation and land management. For the interested reader, InVest, ARIES, and ESII are state-of-the-art software suites that provide guided examples and training.

\section{VALUING NATURE AND GUIDING RESTORATION}

As mentioned in the introduction, a key reason for the invisibility of nature in the decision-making process is the lack of values and prices for the goods and services provided by the natural environment as they are non-marketable goods. Economists have created a set of theoretically derived methods called non-market valuation methods to value the goods and services provided by the environment. 
These methods estimate people's willingness to pay (WTP) for protecting and restoring nature. A brief introduction to these theoretically derived methods is provided below (Haab and McConnell, 2002; Bennet, 2011 and Johnston et al., 2017for details).

Revealed preference valuation methods use existing data from a market linked or related to non-market or environmental goods to value the non-market goods. There are two methods; travel cost and price hedonics. The travel cost method uses cost incurred in travels to measure of value and is typically used to measure parks, recreations sites etc. The scientific assumption is that a resource (time and money) constrained individual will only visit a recreational site if the value of the visit is greater than the cost they incur. For an example, if a family trip to the Yala National Park costs Rs. 10,000, the park must provide a lower bound value of Rs. 10,000 for that family. The cost incurred are typically calculated using both direct monetary and time costs and studies account for multiple socioeconomic factors. The price hedonics method assumes that the value of non-market goods is capitalized into market goods like housing. For an example, houses that are located close to urban amenities such as a clean lakes, urban parks and recreational areas will have higher housing prices compared to similar houses without the amenities.Using statistical analysis to compare these housing prices allows extracting the value or WTP for environmental goods like clean lakes, urban parks etc.

Stated preference valuation methods elicit values from the public using surveys. There are two widely used methods; contingent valuation and choice experiments. The contingent valuation method describes a good and asks questions about their willingness to pay using a survey. As an example, consider showing a lunch-packet to a group and asking them to write down how much they would be willing to pay for the lunch packet. A simple average would provide the sample's average willingness to pay for this lunch packet. One of the earliest contingent valuation studies carried out in Sri Lanka was to understand WTP for the Peradeniya Botanical Gardens and the study was instrumental in changing the entrance fees.

A major limitation of the contingent valuation method is that it does not provide information on component parts or the characteristics of the good being valued. The choice experiment describes the good (or policy) being valued using key attributes and asks the respondent to make choices between options. Further to the lunch packet example, the respondents will be asked to choose between two or more lunch packets where the contents of each lunch packet and the price (the attributes of the good) are systematically varied using experimental design principles. Once the data is analyzed using appropriate discrete choice statistical methods, the results provide information on not only on the value of the lunch packet but also the values of the different components or attributes of the lunch packet (or the non-market environmental goods being valued).

The careful use of these non-market valuation methods allows researchers and policy makers to reduce the invisibility of nature in the process. For an example, using the results from multiple studies, the values obtained from a tropical forest located in Madagascar have been quantified in the TEEB Synthesis Report (2010) as medicines 1.5 million USD, erosion control 380,000 USD, carbon storage 105 million USD, recreation 5.1 million USD, and forest products 4.2 million USD. Based on these values and more importantly the ecosystem functions that provide these values will help the policy makers and practitioners to make much better and more educated decisions to advance development and improve livelihoods while ensuring the nature and the environment.

Sahan T. M. Dissanayake Department of Economics, Portland State University, Oregon, USA and International Union for the Conservation of Nature (IUCN), Sri Lanka E-mail:sdissan2@gmail.com,sahan@pdx.edu

\section{REFERENCES}

Ando, A.W., and M.L. Mallory. 2012. Optimal Portfolio Design to Reduce Climate-Related Conservation Uncertainty in the Prairie Pothole Region. PNAS, 109(17): 6484-6489.

Bennett, J. 2011, The International Handbook on NonMarket Environmental Valuation, Edward Elgar, Cheltenham, UK, pp. 322-352.

Boyd, J., Epanchin-Niell, R., \& Siikamäki, J. 2015. Conservation planning: a review of return on investment analysis. Review of Environmental Economics and Policy, 9(1), 23-42.

Dissanayake, S. T., \& Hennessey, M. K. (2017). Conservation Choices in the Face of Sea-Level Rise: A Case Study on Marsh Migration from Phippsburg, Maine. Agricultural and Resource Economics Review, 46(2), 388-419.

Haab, T.C. and McConnell, K.E. 2002, Valuing Environmental and Natural Resources: The Econometrics of Non-Market Valuation, Edward Elgar, Cheltenham, UK.

Johnston, R. J., Boyle, K. J., Adamowicz, W., Bennett, J., Brouwer, R., Cameron, T. A., ... \& Tourangeau, R. (2017). Contemporary guidance for stated preference studies. Journal of the Association of Environmental and Resource Economists, 4(2), 319-405.

Millennium Ecosystem Assessment, 2005, Millennium Ecosystem Assessment General Synthesis Report: Ecosystems and Human Well-being. Millennium Ecosystem Assessment. https://www. millenniumassessment.org/

TEEB (2010), The Economics of Ecosystems and Biodiversity: Ecological and Economic Foundations, Earthscan, London. http://www.teebweb.org/

Williams J. C., ReVelle C. S., Levin S. A. 2005. Spatial attributes and reserve design models: A review. Environmental Modeling Assessment, 10(3), 163-181. 